\title{
The Emotional Impact of Hotel Room Colour in Spanish and Equatorian Tourists
}

\author{
Mónica P. BUENAÑO ${ }^{\mathrm{a}}$, Lledó MUSEROS ${ }^{\mathrm{b}}$ and \\ Luis GONZALEZ-ABRIL ${ }^{\mathrm{c}}$ \\ ${ }^{\mathrm{a}}$ Universidad Técnica del Norte, ${ }^{\mathrm{b}}$ Universitat Jaume I, \\ ${ }^{\mathrm{c}}$ Universidad de Sevilla
}

\begin{abstract}
Research suggests that colour plays an important role in creating wellness emotions in hotel customers. This paper considers that tourists' needs for wellness may be satisfied by manipulating existing elements of a hotel, such as the colour of a hotel room. The paper studies the relationship between tourists' emotions and the main colour of a hotel room, and also the relationship between that emotion and their intention to stay in the hotel, and even the price that the tourists are willing to pay. Also, the paper studies the role of cultural differences in these relationships, specifically between Spanish and Equatorian tourists.
\end{abstract}

Keywords: colour and emotions, touristic image, tourism marketing, recommender system, data science.

\section{Introduction}

Colour is considered an indispensable element in interior design [1]. It allows designers to alter the characteristics of the environment in an easy and economical way [2], and to create desirable and pleasant environments [3]. It has a strong visual component which is able to attract the client's attention [4]. Furthermore, it is a subtle stimulant with a significant impact on people's emotions and behavior [5-7], and it can increase motivation and well-being [8]. Therefore, colour selection for a hotel room decoration is very important in order to design a comfortable and wellness-oriented environment. In some ways, colour selection of the decoration of a room can guarantee an affective commitment between the client and the hotel [9]. Moreover, these aspects can influence the choice to stay in a hotel, which is a decision made not only on a rational basis but also under emotional and wellness-oriented considerations [10].

The new trends in the demand of hotels in the wellness sector have a direct influence in the generation of new products and services in tourism and hospitality [11]. Luxury hotels with spa facilities are recognized as the leading providers of wellness services [11], but there are also smaller hotels that cannot afford spa and high-cost facilities, but can offer wellness services by finding strategies to meet the needs of wellness travelers and that do not demand large economic investments. In this way, Thus, Dimitrovski \& Todorović [12] propose that wellness tourism should be oriented towards the emotional motivation of the guest instead of using luxurious spas, taking into account that emotion is a key point in the evaluation of personal well-being [13]. Thus, the paper presented in 
this paper proposes the study of the emotional link that the colour of a room can generate in the guests as a tool for small hotels to improve their wellness image.

Research on the emotional impact of colour and behavioral intentions has been developed in different areas. For example, it has been shown that colour on food labels influences emotions, selection and intention to pay more for the product [14]. Wu, Li \& Liu [15] showed that there is a close relationship between the colour of food packages, emotions and user satisfaction. It was also found that the colour of the office and study environment influences emotions, work and learning performance [16].

Approaches in the tourism and hospitality field have studied the relationship between the emotional response to the colour of a restaurant and the intention to choose it and enter [17]. Also, the works presented in [18] demonstrate that guests who reported emotions of comfort, well-being and relaxation can build a relationship of loyalty and intention to pay more for the service. Haller [19] mentions that colour is the first thing that is perceived when entering a room. It can influence behavior, feelings, such as feeling more relaxed, eating more and spending more. Countryman \& Jang [6] demonstrated that colours are the most influential element to affect overall hotel lobby impression. The approaches in [13] specify that guests prefer blue or green as colours for the rooms, since they find these colours more relaxing, and calming and therefore better rooms for having a good quality of sleep and well- being. In fact, these colours are used in luxury hotels to induce pleasure [20]. On the contrary, the colour red has been associated with high levels of arousal and restlessness [21] and therefore it is not recommended as the colour of a hotel room.

Therefore, it is important to study the link between colour, emotion and behavior. To understand this relationship, Mehrabian and Russell SOR model [22] affirms that the physical environment acts as stimuli (S) that lead to people's emotions $(\mathrm{O})$, which in turn, drive behavioral responses (R).

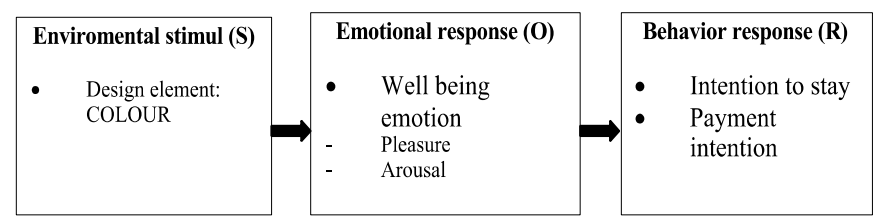

Figure 1. SOR model, relationship between colour stimuli, emotions and behavioral responses

To assess emotional responses to environmental stimuli, Russell and Lanius [23] propose a model (PA model) concerning affective appraisals of environments. It is based on two bipolar dimensions (Pleasantness - unpleasantness; Arousing - not arousing) (Figure 2).

Therefore, this study suggests that through the manipulation of colour in different elements of the physical environment of a hotel room, emotions of well-being can be created, which in turn, drive the intention to stay and the price that one would be willing to pay (Figure 1).

The present study also considers exploring cultural influence in the link between colour and emotions, since emotional responses to colour can be determined by cultural traits. Thus, in this paper the following hypothesis are going to be explored:

H1: The intention to stay is related to colours.

H2: Changes to the colour of the hotel room generate different emotions. 
H3: The intention to stay in the hotel is related to positive emotions.

H4: The price the tourists are willing to pay for a room is related to their nationality.

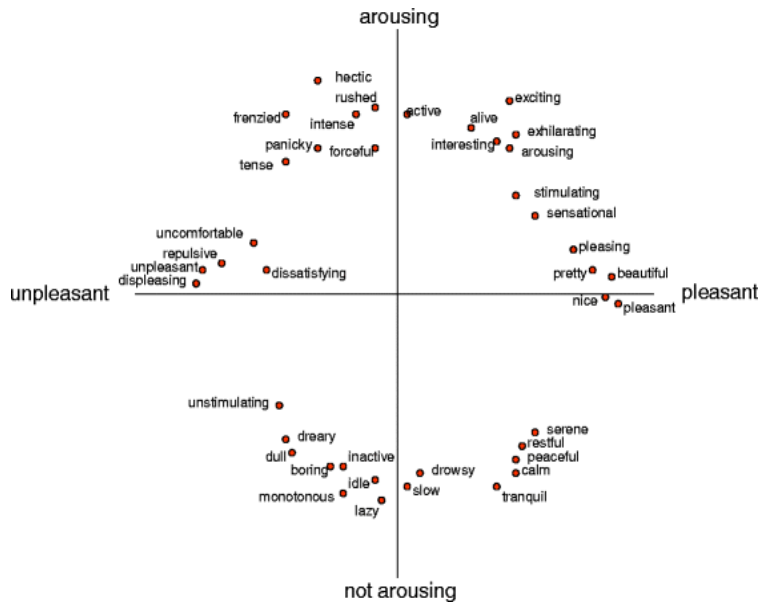

Figure 2. Categorical affective descriptors located in the space for the PA model. Adapted from Russell \& Lanius, 1984

The rest of the paper is organized as follows, first a brief overview of the QCD model used in this approach is presented, then the survey designed for data collection is described. Section 4 analyzes the results collected with the survey to verify the hypothesis defined. Finally, conclusions and future work are presented.

\section{Overview of the Qualitative Colour Descriptor (QCD)}

The QCD model [24] defines a reference system in the HSL colour space for qualitative colour description, which is built according to Figure 3 and defined as:

$$
\mathrm{QC}_{\mathrm{RS}}=\{\mathrm{uH}, \mathrm{uS}, \mathrm{uL}, \mathrm{QCNAME1} . .5, \mathrm{QCINT} 1 . .5\}
$$

where $\mathrm{uH}$ is the unit of Hue; $\mathrm{uS}$ is the unit of Saturation; $\mathrm{uL}$ is the unit of Lightness; QCNAME1..5 refers to the colour names; and QCINT1..5 refers to the intervals of HSL coordinates associated with each colour. The chosen QCNAME and QCINT are shown in Figure 3.b

The QCD model has a relational structure and it can be organized in a conceptual neighborhood diagram (CND) [25] according to how a colour can be transformed into another by changing its luminosity, saturation or hue. A CND for the computational QCD is built and shown in Figure 3(b). 


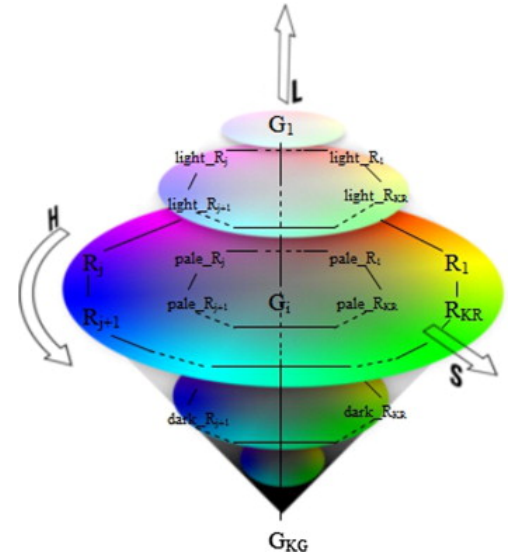

(a)

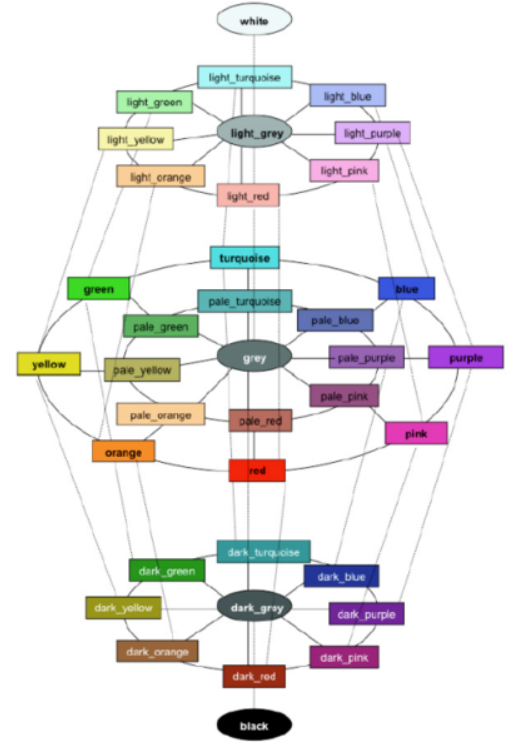

(b)

Figure 3. Diagram for describing QCD: (a) Discretization of the HSL colour space; (b) CND corresponding to QCD.

\section{Design of the Experiment}

An online survey (Figure 5) was designed using the LimeSurvey ${ }^{1}$ software. Using this tool, a survey was designed where 6 demographic questions were defined ( nationality, gender, age, level of education, favourite colour, and number of nights in a hotel during last year). Then the survey presents a set of 9 images of a hotel room (see Figure 4 for examples). There were 3 different types of questions for each image (named base questions). The first question was aimed at determining the relationship between the tourist's emotion and the color of a hotel room, the second question asked for the conative aspect of the tourist (their intention to stay in such a room as the one in the image, it was rated using a five-point Likert scale), and finally the survey asked about the price that the tourist would agree to pay for the room. The first set of questions were based on a basic room at the Hotel Plaza Victoria in Ecuador (Figure 4a), with gray decoration. This room is used also at the end of the test as a control question. Then the colours of decorative elements (group 1: curtain and headboard, group 2: the cushion, footboard, and tablecloth) in the room were colorized using the qualitative colours defined in the QCD model [25]. Following the approaches [13-14], and in order to verify that green and blue colours are prefered by the guests over red colours, the colours green, blue, red and yellow have been chosen for the decoration of the decorative elements of the room. Each set of base questions was made for two rooms decorated with colours with the symbol green (as green, pale green, dark green, or light green) in its label (as in the example in Figure 4b), secondly for two rooms with any blue of the QCD decoration (Figure $4 \mathrm{c}$ ), then a room with any green an any blue decoration (Figure $4 \mathrm{~d}$ ), then a room

\footnotetext{
${ }^{1}$ https://www.limesurvey.org/es/.
} 
with only yellow or red decorations (Figure 4e), and finally a room with red and yellow decoration was presented (Figure 4f). Not all the tourists saw the same image, since the colours of the room were randomly generated using the QCD model. This means that, for instance, the blue colour rooms could present different RGBs colours if the corresponding colour label inside the QCD model had the blue, pale-blue, light-blue or dark-blue label. The same happens with the rest of colours. Therefore, each tourist had to answer the 3 base questions related to 9 images of the same hotel room, but with a different colour. The same room image was used to avoid participant fatigue, and it was verified with the members of the research team that the survey was carried out quickly and without fatigue.

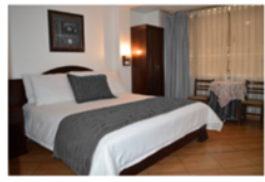

(a)

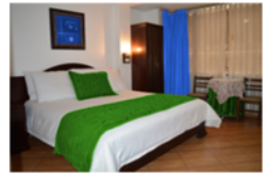

(d)

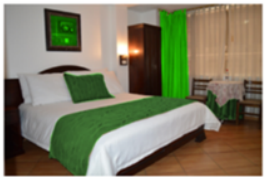

(b)

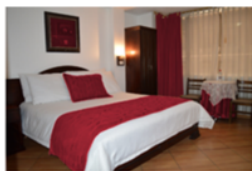

(e)

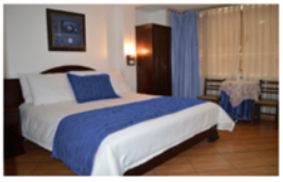

(c)

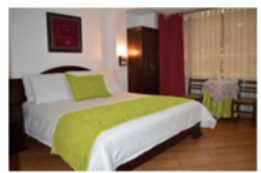

(f)

Figure 4. Examples of images of a hotel room used in the survey.

\section{Data Collection and Analysis}

The experiment was carried out with the collaboration of 239 tourists, mainly Spaniards and Ecuadorians. Analyzing the data collected with the survey, the tourists answering $51.9 \%$ were female, $36.4 \%$ participants were male, and $11.7 \%$ preferred not to say their gender; the age of participants ranged from 18 to 60 years, and $38.9 \%$ had graduate degrees and $38.9 \%$ had postgraduate degrees. The majority $(70 \%)$ of the participants spent 15 or fewer days a year in a hotel room.

Next, the collected results are analyzed in relation with the initial hypothesis defined.

\section{H1: The intention to stay is related to the colours.}

To examine the effects of colours on the intention to stay at the hotel, tourists were asked first to evaluate a room hotel with gray decoration as our basis (gray scale or neutral colour), and $62 \%$ of them answered a positive intention to stay in the hotel (see Table 1). This shows that upon a first observation, the gray decoration is accepted by the tourists. Also gray has been chosen as the baseline colour because it is considered a neutral and practical hue, described as serious or stately and associated with official buildings [26].

Then, by varying the colours of the room, and presenting seven random rooms with different colour decorations to each of the 239 users, 1673 responses were obtained (see Table 1). The results shows that the intention to stay in the same room was $44 \%$, which is lower than the baseline, and indicates that not all colours are suitable for the interior of a room and may have a negative effect. Therefore, due to the difference between these values ( $44 \%$ and $62 \%$ ), the hypothesis is confirmed: the colour of a room significantly influences the intention to stay. 


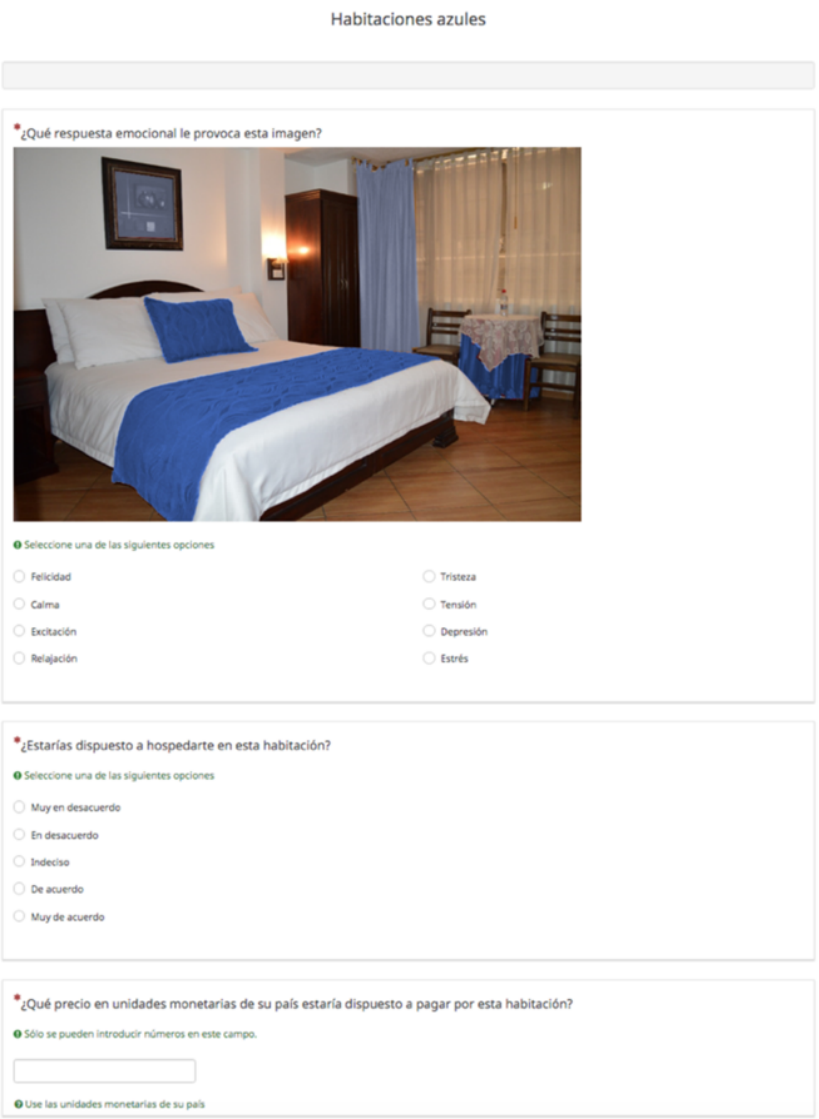

Figure 5. Example of the survey and the base questions for a blue room.

H2: Changes to the colour of the hotel room generate different emotions.

Table 1. Intention to stay and colour

\begin{tabular}{ccccc}
\hline & \multicolumn{2}{c}{ Gray } & \multicolumn{2}{c}{ Colour } \\
\hline & Frecuency & $\%$ & Frecuency & $\%$ \\
Doubt & 057 & 24 & 396 & 24 \\
No & 033 & 14 & 541 & 32 \\
Yes & 149 & $\mathbf{6 2}$ & 736 & $\mathbf{4 4}$ \\
Total & 239 & 100 & 1673 & 100 \\
\hline
\end{tabular}

To examine the effect of the colour change to the base room on the emotional responses based on the PA model, tourists were asked to rate randomly generated room images with combinations of blue, green, red, and yellow colours. A contrast of proportions is used in order to test the hypothesis that changes in the colour of the decoration of the rooms significantly affect and change the emotions of the tourists. For this, if the adjective of the gray room is not changed, the variable takes the value 0 and otherwise 1 (see Table 2). Thus, if colour does not affect emotion, the probability $(p)$ to change the emotions is zero, that is $p=0$, nevertheless the hypothesis is relaxed and the null hypothesis is H0: "Colour does not affect emotions $(p \leq 0.2)$ ". 
The results of the contrast of proportions showed that the $p$-value is close to zero; therefore, the null hypothesis is rejected and hence, it can be concluded that changes in the colour of the room decoration change the emotions. It is important to note that $86 \%$ of responses change the emotion with respect to the gray room.

Table 2. Frequency of change of emotion in relation to different colour decorations for a hotel room.

\begin{tabular}{ccc}
\hline Change emotion & Frecuency & $\mathbf{\%}$ \\
\hline 0 & 242 & $14 \%$ \\
1 & 1431 & $86 \%$ \\
Total & 1673 & $100 \%$ \\
\hline
\end{tabular}

\section{H3: The intention to stay in the hotel is related to positive emotions}

From the responses of the participants, a new variable called "positive emotion" has been created as follows: if the emotions are "Calm", "Happiness", "Relaxation", the positive emotion is 1; if the emotions are "Depression", "Stress", "Tension" and "Sadness" the positive emotion is -1 ; and if the emotion is "Exciting", then the positive emotion is 0 .

Hence, the contingency table between this new variable is given in Table 3. A Chi square test was applied to confirm the relationship between positive emotions and the intention to stay in the hotel and the $p$-value of this test was $1.17 \mathrm{e}-230$, which indicates that the two variables are related.

H4: The price he/she are willing to pay for a room is related to the nationality.

A box plot comparing the price that Spanish and Ecuadorian tourists are willing to pay for a room is shown in Figure 6. To this, all the currency units have been converted to euros $^{2}$ in order to be able to compare the values. It can be seen in Figure 3 that Spaniards are willing to pay more for the room than Ecuadorians.

Table 3. Intention to stay

\begin{tabular}{cccccc}
\hline & & Doubt & No & Yes & All \\
\hline \multirow{3}{*}{ Positive } & -1 & 246 & 496 & 35 & 777 \\
emotion & 0 & 62 & 22 & 88 & 172 \\
& 1 & 88 & 23 & 613 & 724 \\
& All & 396 & 541 & 736 & 1673 \\
\hline
\end{tabular}

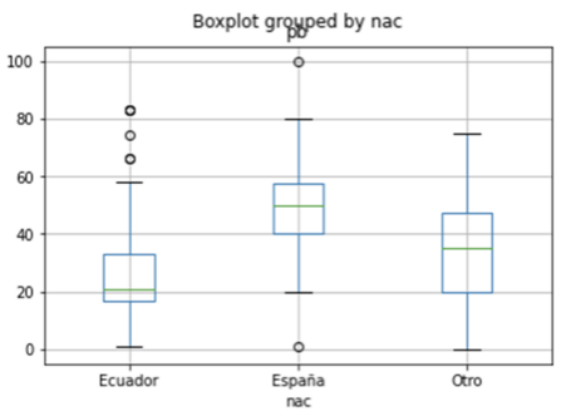

Figure 6. The price that the tourists are willing to pay

\footnotetext{
${ }^{2}$ Change of day $30 / 04 / 2021$
} 
Table 4 shows that on average Spaniards would be willing to pay 49.56 euros, while Ecuadorians would pay 23.62 euros less than Spaniards. This is natural due to the fact that Spaniards have greater purchasing power. This was confirmed by Durán-Román, Cárdenas-García, \& Pulido-Fernández [27], that the willingness to pay to improve the experience in the destination has a direct relationship with the income and budget of the tourists visiting Andalucía. Although income allows paying more for a service, other studies found that nationality had a more significant effect on willingness to pay for some tourism activity than other factors [28], even the foreign visitors' willingness to pay is twice that of domestic visitors' willingness to pay [29].

In order to test the hypothesis, the Mann Whitney Test (test of difference of mean) has been used and a $p$-value of 8.28 e-14 is obtained. Therefore, there is significative difference between the mean values willing to pay for a room between Ecuadorians and Spaniards.

Table 4. Average willingness to pay for a room

\begin{tabular}{cccc}
\hline $\begin{array}{c}\text { Nacionality } \backslash \text { Price } \\
(\boldsymbol{\epsilon})\end{array}$ & Count & Mean & $\begin{array}{c}\text { Standard } \\
\text { deviation }\end{array}$ \\
\hline Ecuador & 177.0 & 25.94 & 15.16 \\
Spain & 43.0 & 49.56 & 18.09 \\
Other & 19.0 & 32.423 & 21.796 \\
\hline
\end{tabular}

\section{Conclusions and Future Work}

This study studied the relation between the colour of the decoration of the room in a hotel and the tourists' emotions. Also, it studied if the colour decoration of the rooms affects tourists' intention to stay in the hotel, and finally it studied the price that tourists are willing to pay for a room and the differences between different cultures: Spanish and Ecuadorian tourists. The findings of the study point out that the colour of a room significantly influences the intention to stay and the emotions evoked by the room. Moreover, the results showed that not all colours are suitable for the interior decoration of a room; therefore, the incorrect selection of the colour for that decoration can affect the tourists' emotions and the intention to stay in the hotel. This reinforces the finding showed in Tantanatewin \& Inkarojrit [33], that expressed that interior design, with colour as the most influential factor, influences the behavior of people.

The findings from this study also show that there is a relationship between positive emotions and the intention to stay in the hotel. And finally, regarding the willingness to pay for a hotel room, the results of this study confirm the initial hypothesis, which established that the price that the tourists are willing to pay for a room is related to their nationality. Our findings indicate that Spaniards are willing to pay more for a room than Ecuadorians.

In general, understanding the link between colour, emotion and behavior can guide hotel managers in selecting the appropriate colour to strategically manipulate guests' emotions and an affective commitment between the client and the hotel. Therefore, the results of this study are important in order to create a recommender system for hotel marketing materials. The future recommender system is intended to be used to raise the impact of the marketing materials among prospective tourists and then improve the touristic image of the hotel. In this way, the recommender system can be also used to design customized materials for different types of clients. 
As future work, the specific colours that enhance tourists' perceptions and emotions and generate a positive emotion increasing their intention to stay in the hotel will be studied. Also, the study will be complemented with the analysis of the mood of a person and its effect on the emotion and behavior.

\section{Acknowledgments}

This project has been funded by the Ministry of Economy and Commerce with project contract TIN2016-88835-RET and by the Universitat Jaume I with project contract UJIB2020-15. Also, this research has been partially supported by the EDITH Research Project (PGC2018-102145-B-C21,C22 (AEI/FEDER, UE)), funded by the Spanish Ministry of Science, Innovation and Universities.

\section{References}

[1] D. Oner Ozdas and M. Kazak, Colour preference between adults and children during a dental treatment session, Physiol. Behav., vol. 169, pp. 165-168, 2017.

[2] L. Sliburyte and I. Skeryte, What we know about consumers' color perception, Procedia - Soc. Behav. Sci., vol. 156, pp. 468-472, 2014.

[3] M. Heide, K. Laerdal, and K. Grønhaug, The design and management of ambience-Implications for hotel architecture and service, Tour. Manag., vol. 28, no. 5, pp. 1315-1325, 2007.

[4] J. A. Bellizzi and R. E. Hite, Environmental Color , Consumer Feelings, and Purchase Likelihood, Psychol. Mark., vol. 9, no. 5, pp. 347-363, 1992.

[5] J. Barsky and L. Nash, Evoking emotion: Affective keys to hotel loyalty, Cornell Hotel Restaur. Adm. Q., vol. 43, no. 1, pp. 39-46, 2002.

[6] C. C. Countryman and S. Jang, The effects of atmospheric elements on customer impression : the case of hotel lobbies, Int. J. Contemp. Hosp. Manag., vol. 18, no. 7, pp. 534-545, 2006.

[7] S. Han, D. Choi, and Y. J. Cha, The Effect of Colour on the Anchoring Heuristic in Consumer Decision Making, J. Eur. Psychol. Students, vol. 3, no. 10, pp. 19-27, 2014.

[8] C. Yu and H. Yoon, The role of colour in 'health and wellbeing' of the built environment, Indoor Built Environ., vol. 19, no. 4, pp. 403-404, 2010.

[9] H. Choi and J. Kandampully, The effect of atmosphere on customer engagement in upscale hotels: An application of S-O-R paradigm, Int. J. Hosp. Manag., no. June, 2018.

[10] J. Cheng, T. Tang, H. Shih, and T. Wang, Designing lifestyle hotels, Int. J. Hosp. Manag., vol. 58, pp. 95-106, 2016.

[11] H. Han, K. Kiatkawsin, H. Jung, and W. Kim, The role of wellness spa tourism performance in building destination loyalty: the case of Thailand, J. Travel Tour. Mark., vol. 8408, pp. 1-16, 2017.

[12] D. Dimitrovski and A. Todorović, Clustering wellness tourists in spa environment, Tour. Manag. Perspect., vol. 16, pp. 259-265, 2015.

[13] A. Hee Lee, B. Denizci Guillet, and R. Law, Tourists' emotional wellness and hotel room colour, Curr. Issues Tour., pp. 1-7, 2016.

[14] M. Shen and Z. Gao, Blue or red? how color affects consumer information processing in food choice, in Agricultural \& Applied Economics Association Annual Meeting, 2016, pp. 1-14.

[15] T. Wu, Y. Li, and Y. Liu, Study of color emotion impact on leisure food package design, vol. 714, 2017, pp. 612-619.

[16] N. Savavibool, The Effects of Colour in Work Environment: A systematic review, Environ. Proc. J., vol. 1, no. 4, p. 262, 2016.

[17] W. Tantanatewin and V. Inkarojrit, The influence of emotional response to interior color on restaurant entry decision, Int. J. Hosp. Manag., vol. 69, pp. 124-131, 2018.

[18] A. Wong, The role of emotional satisfaction in service encounters, Manag. Serv. Qual. An Int. J., vol. 14, no. 5, pp. 365-376, 2004.

[19] K. Haller, Colour in interior design, in Colour Design: Theories and Applications, Woodhead Publishing Limited, 2012, pp. 551-584.

[20] D. Kim, H. Hyun, and J. Park, The effect of interior color on customers' aesthetic perception, emotion, and behavior in the luxury service, J. Retail. Consum. Serv., vol. 57, no. July, p. 102252, 2020. 
[21] C. Jin, H. Noguchi, J. Qiu, H. Wang, Y. Sun, and Y. Lin, The effect of color light combination on preference for living room, in 12th China International Forum on Solid State Lighting (SSLCHINA), 2015, pp. 139-142.

[22] A. Mehrabian and J. Russell, An approach to environmental psychology, Cambridge, MAMIT Press, 1974.

[23] J. A. Russell and U. F. Lanius, Adaptation level and the affective appraisal of environments, J. Environ. Psychol., vol. 4, no. 2, pp. 119-135, 1984.

[24] Z. Falomir, L. Museros, and L. Gonzalez-Abril, A model for colour naming and comparing based on conceptual neighbourhood. An application for comparing art compositions, Knowledge-Based Syst., vol. 81, pp. 1-21, 2015.

[25] Freksa C. Spatial computing. Cognitive and Linguistic Aspects of Geographic Space: New Perspectives on Geographic Information Research. In: Raubal M, Mark DM, and Frank AU, editors. Berlin: Springer Berlin Heidelberg. p. 23-42, 2013.

[26] S. Kurt and K. K. Osueke, The effects of color on the moods of college students, SAGE Open, vol. 4, no. 1, p. $215824401452542,2014$.

[27] J. L. Durán-Román, P. J. Cárdenas-García, and J. I. Pulido-Fernández, "Tourists' willingness to pay to improve sustainability and experience at destination," J. Destin. Mark. Manag., vol. 19, no. January, 2021.

[28] M. Reynisdottir, H. Song, and J. Agrusa, "Willingness to pay entrance fees to natural attractions: An Icelandic case study," Tour. Manag., vol. 29, no. 6, pp. 1076-1083, 2008.

[29] S. Piriyapada and E. Wang, "Modeling Willingness to Pay for Coastal tourism resource protection in ko Chang Marine National Park, Thailand,” Asia Pacific J. Tour. Res., vol. 20, no. 5, pp. 515-540, 2015. 